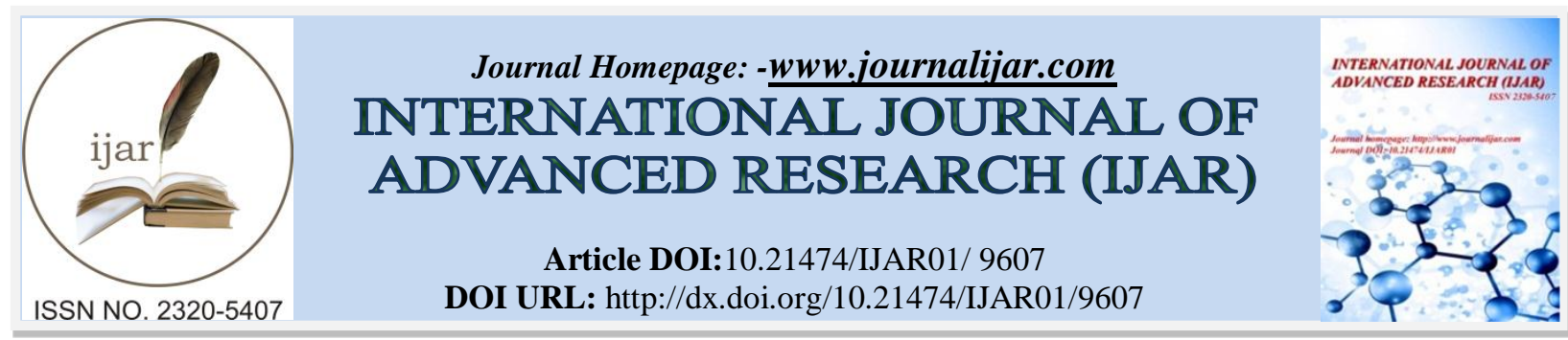

RESEARCH ARTICLE

\title{
PREDICTORS FOR SUCCESSFUL LABOUR INDUCTION WITH PGE2 IN PRIMIGRAVIDA.
}

\author{
Afnan mesfer al-otiabi ${ }^{1}$ and Farzana Rizwan arain $^{2}$. \\ 1. Assistant lecture,Taif medical college,Taif university, KSA. \\ 2. M.B.B.S, M.C.P.S, F.C.P.S,Professor of obstetrics \& gynecology,Obstetrics \& gynecology department, Taif \\ medical college, Taif university .KSA.
}

\section{Manuscript Info}

Manuscript History

Received: 20 June 2019

Final Accepted: 22 July 2019

Published: August 2019

Key words:-

prostaglandine2, labor

induction, cesarean birth.

\section{Abstract}

Objective: To identify independent predictors of successful labor induction With PGE2 in Primigravidas.

Methods: This retrospective study was, conducted at KAASH Hospital, TAIF, KSA. The Medical and Nursing Records of 401 Nulliparous Parturient who received PGE2 Gel for induction of labour conducted at KAASH Hospital from January 2015 to December 2015 were retrospectively reviewed. Data from medical records in the time of the study were collected for four hundred one PG's who were admitted with documented indications for induction of labour. the administered doses of Prostin including the initial dose and the repeated doses till successful cervical dilatation and effacement and starting of labour process were recorded .

The study was performed to Identify factors independently associated with successful labour induction which was defined as vaginal delivery within 24-48 hours either spontaneous or ventouse assisted vaginal delivery. Predictors of Caesarean birth and the need for only one dose of prostin were also identified. Factors included in the study were maternal age, BMI, membrane status, the dose of PGE2, gestational age, birth weight and epidural analgesia.

Results. During the study period from January to December 2015. The total number of PG's whom induced by PGE2 was 401 out of them 270 $(67.3 \%)$ were NSVD $70(17.5 \%)$ ventouse and $61(15.2 \%)$ LSCS.

\section{Conclusion:}

Characteristics of the woman i.e. BMI, fetal weight and some of the individual components membrane status and gestational age, were having impact on successful/failed labor induction in form of NVD or lower segment caesarean section respectively .

Copy Right, IJAR, 2019,. All rights reserved.

\section{Introduction:-}

Labour have been well introduced in the history, Hippocrates' described it as the mechanical dilation and stimulation of the cervical canal (1). Soranus also practiced a number of ways to induce labour, which included artificial rupture of membrane during the second century AD. In 1906, it was noted by Dale that myometrial contractions are caused by the infundibular lobe of pituitary gland (2). Prostaglandins were first reported for labour 
induction by Karim in 1968, with different forms of administration started to be in practice for labor induction (5). Prostaglandins can induce myometrial contractility; therefore, it has been considered the key mediators for the onset of labor.

Prostaglandin offers a great advantage of cervical ripening promotion and myometrial contractility stimulation during the induction of labor with different group of classes, doses and routes of administration. The most common class used is Dinoprostone (PGE2) in obstetrics. It plays a crucial role in maintaining labor, as well as in the cervical ripening process. Two routes have been generally used in PGE2 administration: intracervical and intravaginal. The Food and Drug administration (FDA) approved the intravaginal administration of dinoprostone PGE2 (11) (12). The commercial dinoprostone gel 3g (2.5 ml) contains Dinoprostone $1 \mathrm{mg}$ - Triacetin and Colladal silicondioxide gel in a prefilled applicator.

The drug absorption starts within 30-45 minutes of application. While, repeated doses may be given at 6-hour intervals, with a maximum 24-hour dose of 2 Dinoprostone (13).

It is mentioned that failed induction is the failure of establishing labour after one cycle of treatment, consisting of the insertion of two vaginal PGE2 tablets $(3 \mathrm{mg})$ or gel (1-2 mg) at 6-hourly intervals, or one PGE2 controlled released pessary (10 $\mathrm{mg})$ over 24 hours (14).

\section{Patients and Methods:-}

This retrospective study was, conducted at KAASH Hospital, Taif KSA. After the approval of local ethics committee. The Medical and Nursing Records of 401 Nulliparous Parturient who received PGE2 Gel for induction of labor conducted at KAASH Hospital from January 2015 to December 2015 were retrospectively reviewed.

\section{Inclusion criteria:}

all Nulliparous women at any maternal age, any gestational age, singleton, viable, cephalic presentation, who were not in established labor and with medical or obstetrics indications for labor induction including (the post term $\geq 41$ week, decrease fetal movement, IUGR, Oligohydramnios, PROM, diabetes, hypertension and mild/moderate PET).were included in study .

Exclusion criteria Multiple pregnancies, IUFD and non-vertex presentation were excluded from the study.

These women were placed on the hospital protocol in which the initial dose of PGE2 GEL administered is 0.5 to 1 $\mathrm{mg}$ and the dosing intervals range between 6 to 8 hours. If cervical ripening (dilatation $\geq 3 \mathrm{cms}$ ) or active labor did not occur, repeated doses were given to a maximum of $4 \mathrm{mg}$, no more than $4 \mathrm{mg}$ was permitted.

If cervical dilatation $\geq 3 \mathrm{~cm}$, patient started to have continuous fetal cardiac tracing in the labor ward then Oxytocin was administered intravenously by a standardized incremental infusion protocol to a maximum of $20 \mathrm{mU} / \mathrm{min}$. until the patient progresses and delivered vaginally, which considered and recorded also successful induction.

\section{Data Collection and Analysis:}

Data was collected from medical records, to assess the effect of each factor on the outcome of the induction process, statistical presentation and analysis of the different data was conducted, using the mean, standard deviation, and student t-test.

\section{Results:-}

During the study period from January to December 2015. The total number of PG's whom induced by PGE2 was 401 out of them $270(67.3 \%)$ were NSVD 70 (17.5\%) ventouse and 61 (15.2\%) LSCS.

The monthly distribution of different mode of deliveries among PG's after IOL is shown (Figure 1), while total number of NSVD's 270 women (67.3\%), Ventouse 70 women (17.5\%) and LSCS 61 women (15.2\%) among PG's after IOL (Figure 2).

Comparison between NSVD's, ventouse and LSCS deliveries in regards to different maternal age groups, with women $<20$ years old, there was 26 women $(81.3 \%)$ had NSVD's compared with 2 women $(3.1 \%)$ who delivered by 
LSCS, while NSVD's decreased significantly as maternal age increased, from 21-30 years old and 31-40 years old were 218 women $(67.5 \%) 25$ women $(56.8 \%)$ respectively. Compared with LSCS incidence which increased significantly as maternal age increased. 48 women (14.9\%) between 21 -30years old had lscs and 12 women (27.3\%) at age 31-40 years old. >40 years old 2 women only, one delivered normally, and one by ventouse. This was not significantly statistically $(\mathrm{P}$-value $=0.099)$. Ventouse delivery was not affected almost by maternal age $($ Table 1 , Figure 1).

Comparison between NSVD's, Ventouse and LSCS deliveries in regards to deliveries in different gestational age. One woman less than 32 weeks gestation delivered by LSCS (100\%), between 33-36 weeks 11 women (64\%) delivered normally while 4 women $(23.3 \%)$ delivered by LSCS. In contrast at 37-40 weeks gestation 150 women (72.5\%) delivered normally and 19 women $(9.1 \%)$ delivered by LSCS at $\geq 41$ weeks, normal deliveries were 109 women (61.9\%), compared to 37 women (21\%) LSCS deliveries which was statistically significant at this group (PValue $=0.008)$. While ventouse deliveries were not affected by gestational age was $(11.8 \%, 18.4 \%$ and $17.1 \%)$ respectively (Table 2, Figure 4).

Comparison between NSVD's Ventouse and LSCS deliveries in regards to different babies weight; which shows slightly decrease in the NSVD's as baby weight increase compared with significant increase in the LSCS as weight increase. When babies weight $>2.5 \mathrm{~kg}$ and between $2.5-3.5 \mathrm{~kg}$. NSVD's was $17 \%(68 \%)$ and 206 women (69.4\%) respectively which decrease to 41 women $(59.4 \%)$ between $3.5-4 \mathrm{~kg}$ and 6 women $(60 \%)$ at $>4 \mathrm{~kg}$. In contrast LSCS were 4 women $(16 \%)<2.5 \mathrm{~kg}, 41$ women $(13.8 \%)$ at weight $2.5-3.5 \mathrm{~kg}$ which increase, to 13 women $(18.9 \%$ ) between $33.5-4 \mathrm{~kg}$ with rises of incidence of LSCS $>4 \mathrm{~kg} 3$ women (30\%) which was statistically not significant $(\mathrm{P}-\mathrm{Value}=0.613)$. On the other hand, ventouse delivery was unrelated to the infant weight as highest incidence was at weight between $3.5-4 \mathrm{~kg}, 15$ women $(21.7 \%)$, while decreased to one women account $(10 \%)>4 \mathrm{~kg}$ (Table 4, Figure 6).

Comparison between NSVD's Ventouse and LSCS deliveries in regards to membrane state which shows slightly increase in the incidence of NSVD's 104 women (73\%) with SROM over intact membrane 166 women (63.8\%). In contrast LSCS was significantly increased with intact membrane compared with SROM as was, 48 women (18.5\%) and 13 women $(9.2 \%)$ respectively which statistically significant (P-Value 0.039$)$ while ventouse delivery show no difference (Table 5, Figure 7).

Comparison between NSVD's, Ventouse and LSCS deliveries. In regards to different doses of Prostin Gel, which shows constant decrease in the incidence of NSVD's as prostin gel doses increased compared with significantly increase of LSCS as prostin doses increased as highest incidence of NSVD's was 150 women (74.3\%) who received up to $1 \mathrm{mg}$ prostin only and lowest incidence was 29 women (43.9\%) who received 3-4 mg prostin. While LSCS incidence was 20 women $(9.9 \%), 19$ women (14.3\%) and 22 women (33.4\%) who received up to $1 \mathrm{mg},>1-3 \mathrm{mg}$ and $3-4 \mathrm{mg}$ prostin respectively which was statistically highly significant (P-Value <0.001) In contrast ventouse delivery was not significantly affected by prostin doses except with high dose 3-4mg women (22.7\%) (Table 7, Figure 9).

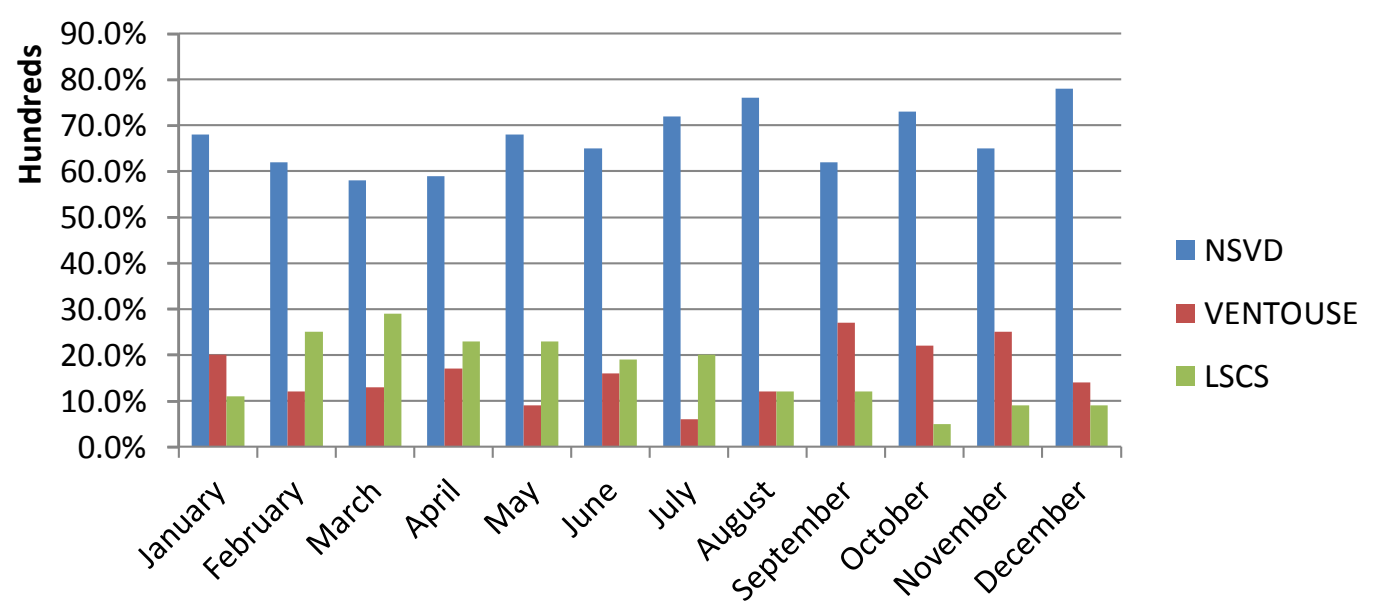

Figure 1:-Monthly Distribution of different mode of deliveries among PG's IOL in KAASH Hospital 2015 


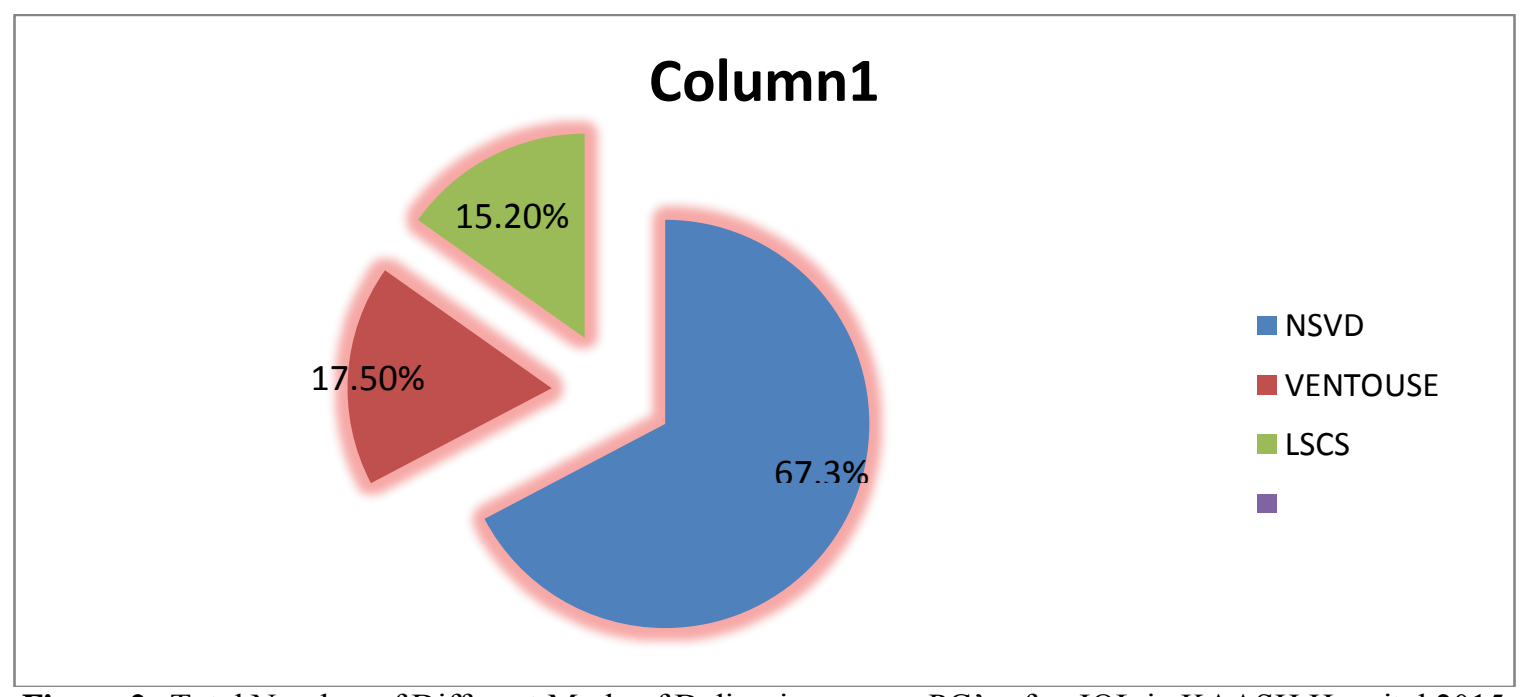

Figure 2:-Total Number of Different Mode of Deliveries among PG's after IOL in KAASH Hospital 2015

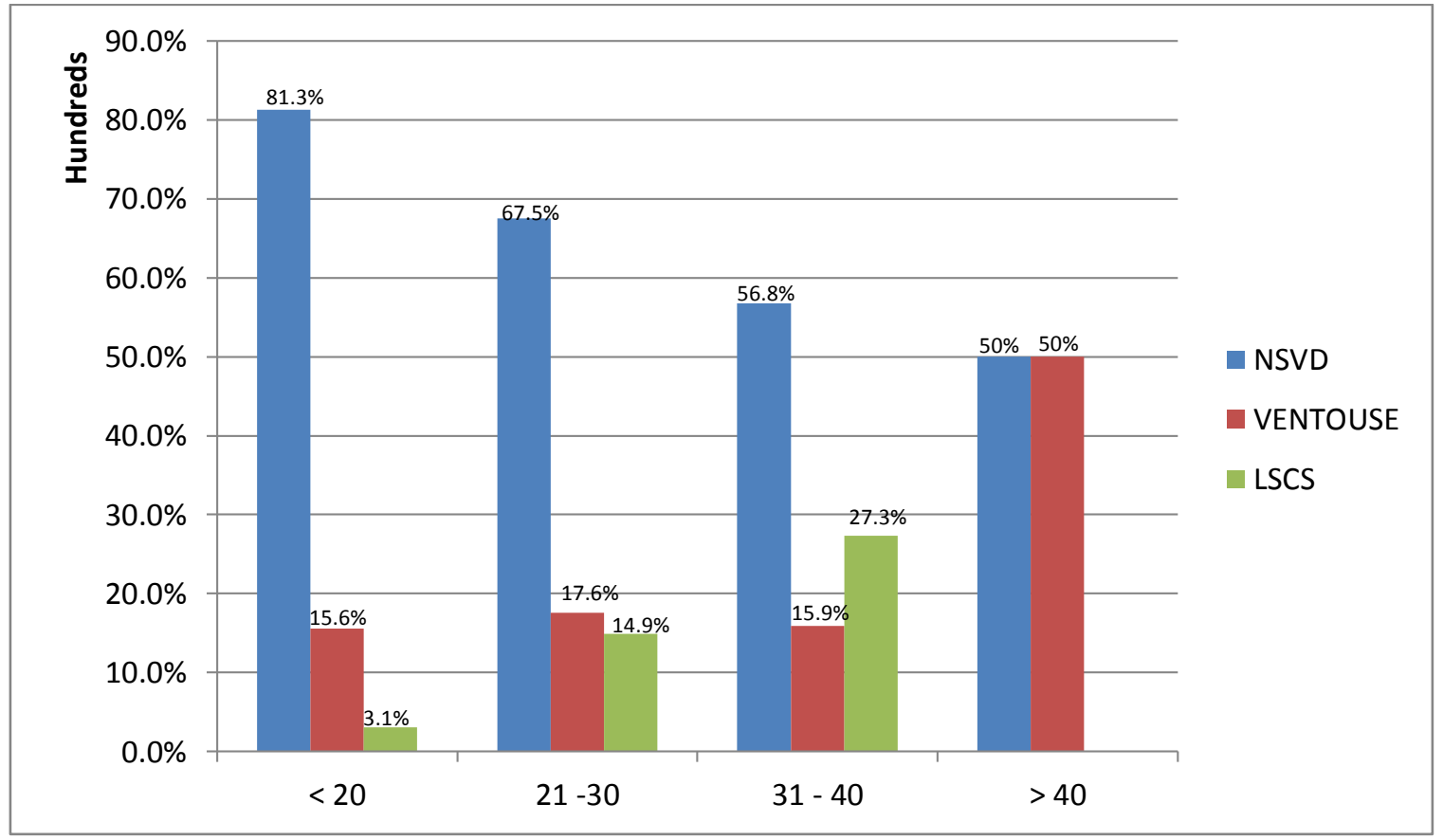

Figure 3:-Comparison between NSVD's, Ventouse and LSCS deliveries in regards to different Maternal Age 


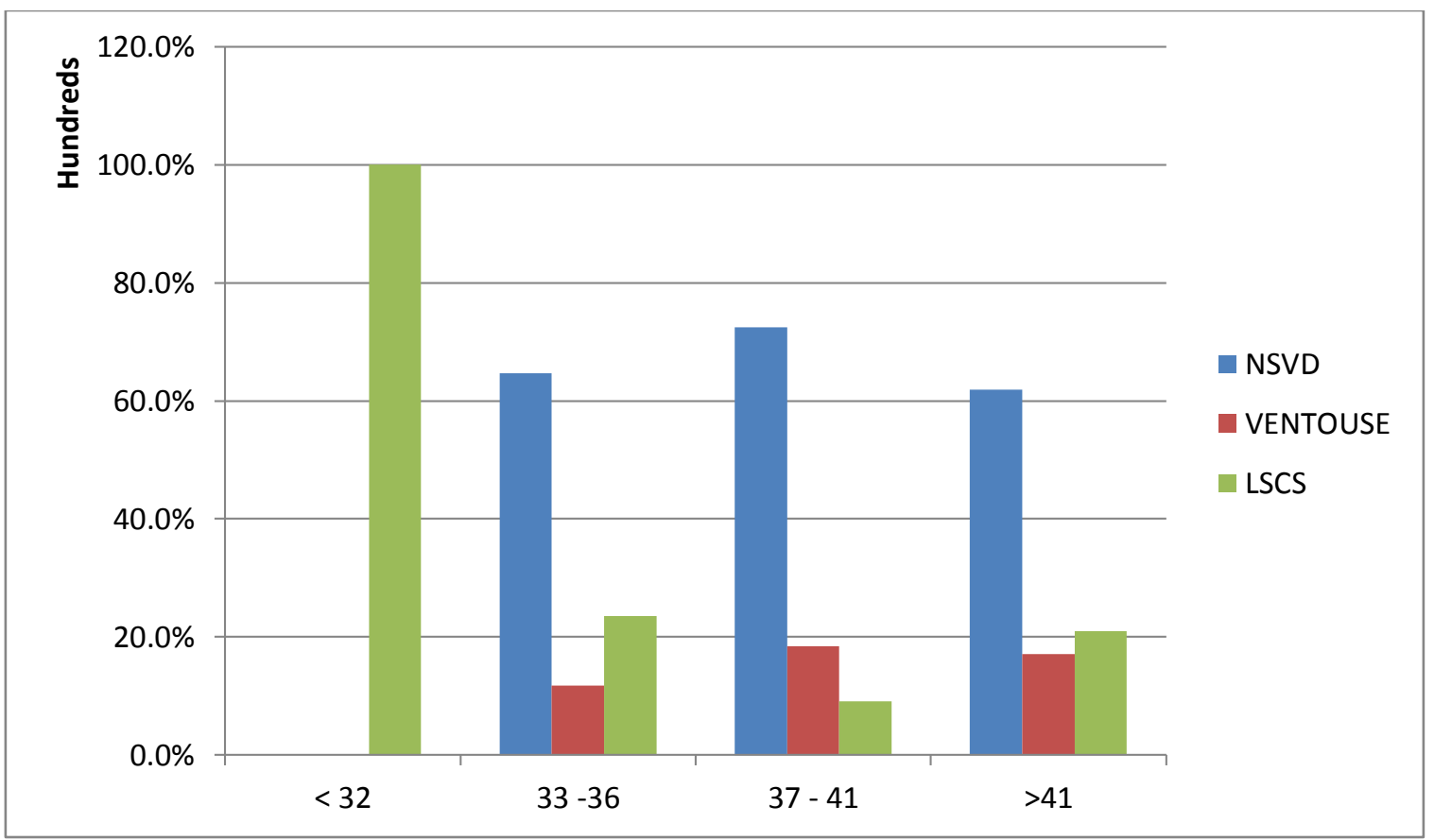

Figure 4:-Comparison between NSVD's, Ventouse LSCS deliveries in regards to different Gestational Age

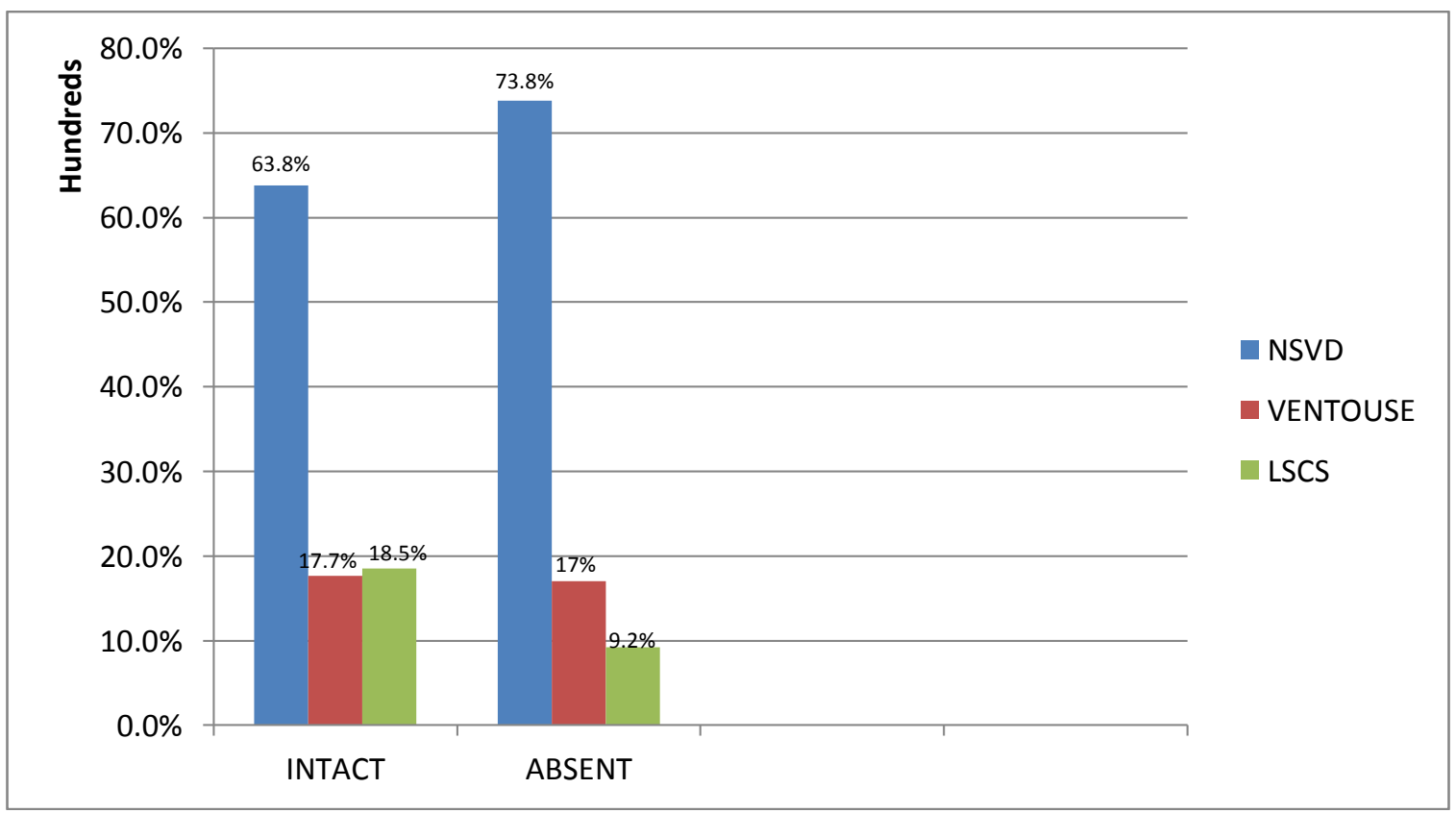

Figure 7:-Comparison between NSVD's Ventouse and LSCS deliveries in regards to different Membrane State 


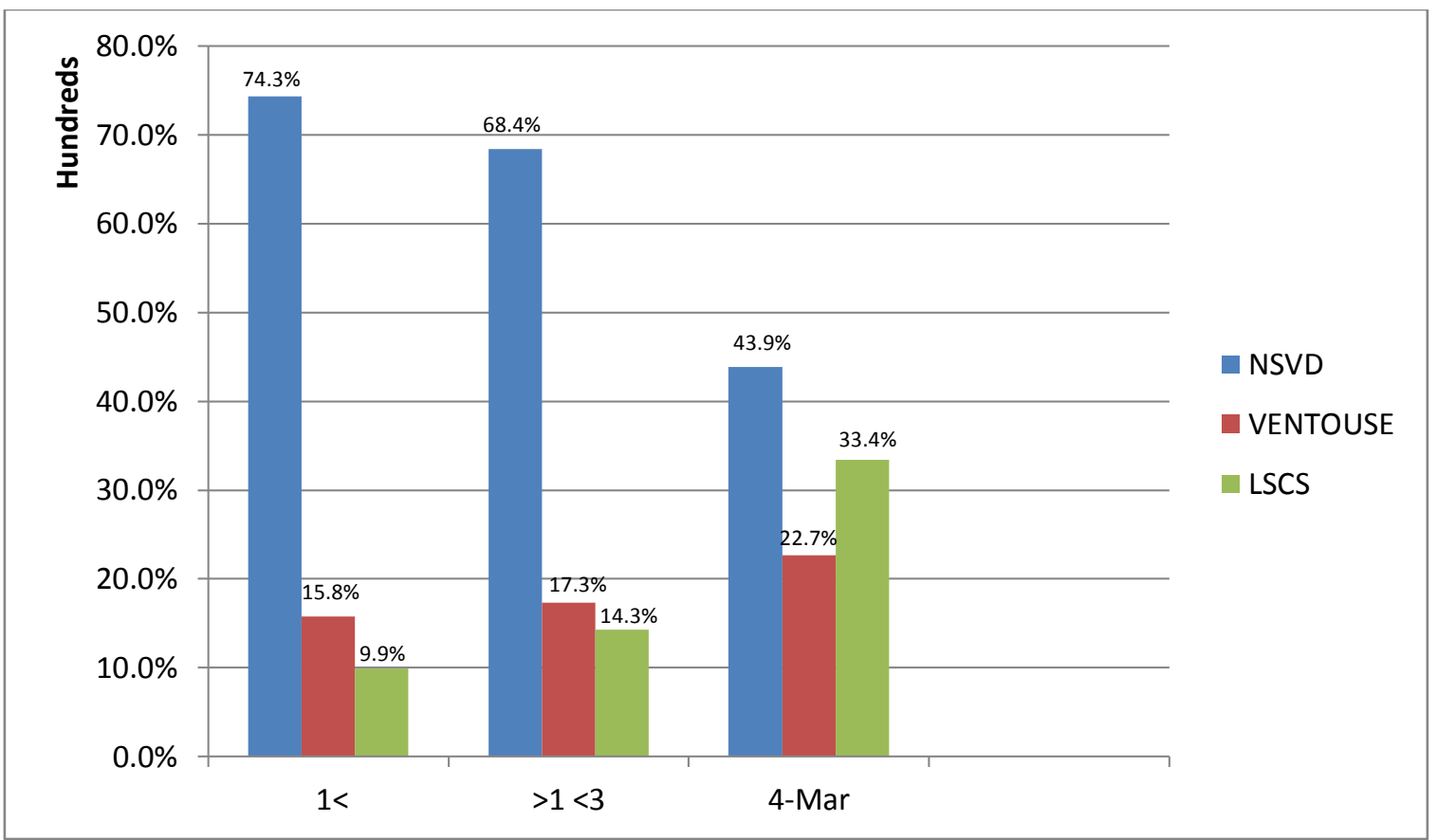

Figure 9:-Comparison between NSVD's Ventouse and LSCS deliveries in regards to different doses of Prostin Gel

\section{Discussion:-}

This study had a major finding; NSVD's rate increased with advanced maternal age but not statistically significant, our findings are similar to the repeated issues encountered in the overall literature regarding maternal age and the risk of caesarean delivery. Two retrospective cohort studies reported an increase in caesarean delivery in women over the age 35 as compared to women younger than 35 years old.

We found that rate of LSCS had been increased with advanced maternal age but not statistically significant, this finding shows the trending issue in the overall literature regarding maternal age and the risk of caesarean delivery. As two retrospective cohort studies reported an increase in caesarean delivery in women over the age of 35 as compared to women younger than 35 years old.

Another prospective cohort study by Tan and colleagues was conducted in Malaysia between January 2003 and August 2004. This study included 152 women who had an induction of labor. In this cohort, there was no significant Difference in caesarean delivery rates between women who were less than 35 years (24.0 percent) compared with women who were greater than or equal to 35 years (19 percent) of age (20). In another prospective study conducted between 1974 and 1981, Orhue and colleagues examined 1,775 women who had induction of labor in Nigeria and found that maternal age greater than 35 years was not associated with increased caesarean delivery (21). These observational studies presented conflicting data to support maternal age as a predictor of caesarean delivery. Thus, the direction of effect could not be adequately determined based on the literature reviewed and the evidence was rated as insufficient.

The connection may reflect a definite biological difference seen between old and young women. For example, older women are susceptible to experience obstetric complications such as, gestational hypertension, preeclampsia and gestational diabetes. Nevertheless, old maternal age has been reported to have a dysfunctional myometrium, which in return leads to a higher incidence of failure in labour $(22,23)$.

Our study reports lower rate of LSCS with term pregnancy (37 - 41 weeks) and a higher rate of LSCS with preterm and post a term group which was statistically significant. These findings are generally consisted with four cohort studies examined gestational age at delivery as a predictor of caesarean delivery in women who underwent induction of labor compared to spontaneous labor. Overall, there was a trend of increasing frequency of caesarean delivery with increasing gestational age. 
Another large retrospective cohort study of 6,985 women, conducted in Canada, observed that caesarean frequency increased from 18.5 percent when delivery occurred between 39 and 40 weeks gestation to 23.9 percent at 41 weeks gestation, and was as high 44.6 percent when delivery occurred during 42 weeks and beyond (28) Similarly, another cohort study reported women who delivered at 40 weeks or less also had a caesarean frequency (18.9 percent) lower than of women who delivered at greater than 40 weeks (27.4 percent) (20).

In another study emphasizing on gestational age and induction of labor, it was found that there was non-significant decrease in the rate of caesarean delivery in patients having their labour induced. OR 0.92; 95 percent CI $0.76-$ 1.12). Meanwhile, in the same group of study, women $<41$ week of gestation there was a reduction in rate of caesarean in the elective induction setting (OR 0.58 percent CI $0.34-0.99$ ), which was statistically significant finding (29).

We had found in our study constant slightly increased rate of LSCS as fetal weight was increased with obvious increase when fetal weight reaches more than $4 \mathrm{~kg}$ which was not statistically significant. It was reported in four cohort studies that examined gestational age at delivery, the continuous fetal growth progression in return, increase the chance of cephalon-pelvic disproportion with increased gestational age. These findings have been demonstrated in term pregnancies in a study of labouring women (30).

The effect of SROM was statistically highly significantly as vaginal delivery rate increased and LSCS rate decreased with women who had ruptured membrane when compared with women who had intact membrane before induction labour started.

There was statistically highly significant lower rate of vaginal deliveries compared with higher rate of ventouse deliveries with epidural analgesia, but not affecting the rate of LSCS. Which correlated with a Cochrane review published in 2005 showed that epidural analgesia was associated with an increased risk of instrumental vaginal birth (pooled RR 1.38, 95\% CI 1.24 -1.53) compared with deliveries with non-epidural analgesia or no analgesia (31).

A land mark study by Wong et al. (32) published in 2005 provided evidence that epidural analgesia does not cause increased rate in LSCS rate in nulliparous women. We noticed higher vaginal deliveries with the use of lower dose of prostin of less than $1 \mathrm{mg}$, compared with higher rate of LSCS with the use of higher doses of prostin which was statistically highly significant.

\section{Conclusion:-}

It has been concluded from the study that young age, low BMI, low fetal weight, increase gestational age and SROM prior induction can be considered as good predictors for successful induction of labour in PG's.

\section{References:-}

1. De Ribes C. De l'Accouchement Provoque, Dilatation du Canal Genital a l'Aide de Ballons introduits dans la Cavite Uterine Pendant la Grossese. Paris, Steheil, 1988.

2. Dale HH. On some physiological actions of ergot. J Physiol 1906; 34: 163-206.

3. Bell WB. The pituitary body. BMJ 1909;2: 1609-13.

4. Page EW. Response of human pregnant uterus to Pitocin tannate in oil. Proc Soc Exp Biol 1943;52: 195-7.

5. Karim SMM, Trussele RR, Patel RC, Hillier K. response of pregnant human uterus to prostaglandin $\mathrm{F}^{2}$ alpha induction of labour. BMJ 1968; IV: 621-3.

6. Macer J. Buchanan D. Yonekura ML, induction of labor with prostaglandin

7. Gordon-Wright AP, Elder MG. Prostaglandin E2 tablets used intravaginally for the induction of labor. $\mathrm{Br} \mathrm{J}$ Obstet Gynecol 1984; 63:664-8.

8. Yan X, Sun M, and Gibb W. Localization of nuclear Factor -B (NF B) and Inhibitory Factor B (I B) in Human Fetal Membranes and Decidua at Term and Preterm Delivery. Placenta 23:288 - 293(2002)

9. Challis JRG, Matthews SG, Gibb W, Lye SJ. Endocrine and Paracrine Regulation of birth at Term and Preterm. EndocRev. 21:514-550 (2000)

10. Gibb W. Challis JRG. Mechanisms of term and preterm labor. J Obstet Gynecol Can. 24:874-883 (2002)

11. Sanchez-Ramos L, Farah L.A, Kaunitz AM, et al. Preinduction cervical ripening with commercially available prostaglandin E2 gel: A randomized, double blind comparison with a hospital compound preparation. Am J Obstet Gynecol 1995; 173: $1079-84$. 
12. Stempel JE, Prins RP, Dean S. Preinduction cervical ripening: A randomized prospective comparison of the efficacy and safety of intra cervical prostaglandin E2 gel. Am J Obstet Gynecol 1997; 1176:1305-9.

13. Sanchez-Ramos, L, kaunitz, A,Glob. Libr.women's med., (ISSN: 1756-22228) 2009; DOI 10.3843/GLOWM.101

14. Pharmacology 2007. Rang, Ritter, Dale, Flower. Churchill Livingstone Elsevier

15. Votta RA and Ciblis LA. Activemanagement of prolonged pregnancy. American Journal of Obstetrics and Gynecology 1993;168 (2); 557-63.

16. Crane, JOAN M. Clinical Obstetrics and Gynecology: September 2006 - Volume 49 - Issue 3 -pp 573-584.

17. Gopalani S, Bennet K, Critchlow C. Factors predictive of failed operative vaginal delivery. Am J. obstet Gynecol. 2004 Sep;191 (3); 896-902.

18. Clinical Guideline July 2008 Funded to produce guidelines for the NHS by NICE.

19. WHO, 2000 and National Institute of Clinical Excellence, UK-NICE, 2006

20. Tan PC, Suguna S, Vallikannu N, Hassan J. Ultrasound and clinical predictors for Ceasarean delivery after labour induction at term. Aust N Z Obstet Gynaecol.2006

21. Orhue AA, Unuigbe JA, Ezimokhal M. Ojo VA. Outcome of induced labour in 931 term Pregnancies. Obstet Gynaecol.1984 Jul;64(1);108-114.

22. Greenberg MB. Cheng YW, Sillivan M. Norton ME, Hopkins LM, Caughey AB. Does length of labour vary by maternal age. Am J Obstet Gynecol.2007 Oct;197(4):e421-427.

23. Caughey AB, Stotland NE, Washington AE, Escobar GJ. Maternal and obstetric of complications pregnancy are associated with increasing getational age term. Am J Obstet Gynecol. 2007 Feb;196(2):e151-156

24. Nutthalapathy FS, Rouse DJ, Owen J. The association of maternal weight with caesarean risk, labour duration, and cervical dilation rate during labour induction. Obstet Gynecol.2004 Mar;103(3);452-456.

25. Stotland NE, Hopkins LM, Caughey AB. Gestational weight gain, macrosomia, and risk of caesarean birth in nondiabetic nulliparas. Obstet Gynecol.2004 Oct;104(4):671-677.

26. Stotland NE, eashington AE, Caughey AB. Preprenancy body mass index and the length of gestation at term. Am J Obstet Gynecol. 2007 Oct;197(4):378. E371-375.

27. Weiss JL, Malone FD, Emig D. et al. Obesity, Obstetric complications and caesarean delivery rate- a population-based screening study. Am J Obstet Gynecol.2004.

28. Boyd ME, Usher RH, McLean FH, Kramer MS. Obstetric consequences of postmaturity. Am J Obstet Gynecol. 1988 Feb;158(2):334-338.

29. Gulmezoglu AM, Crowther CA, Middleton P. Induction of labour for improving birth outcomes for women at or beyond term. Cochrane Database Syst Rev.2006(4):CD004945.

30. Nesbitt TS, Gilbert WM, Herrchen B. Shoulder dystocia and associated risk factors with macrosomic infants born in California . Am J Obstet Gynecol.1998 Aug;179(2):476-480.

31. Anim-Somuah M. Smyth R. Howell C Epidural versus non-epidural or no analgesia in labour. Cochrane Database Syst Rev 2005;4:CD000331. 